\title{
Time-dependent spalling behavior of thermally grown oxide induced by room temperature interfacial deformation
}

DOI:

10.1016/j.surfcoat.2017.11.037

\section{Document Version}

Accepted author manuscript

Link to publication record in Manchester Research Explorer

\section{Citation for published version (APA):}

Xiao, P. (2018). Time-dependent spalling behavior of thermally grown oxide induced by room temperature interfacial deformation. Surface and Coatings Technology. https://doi.org/10.1016/j.surfcoat.2017.11.037

\section{Published in:}

Surface and Coatings Technology

\section{Citing this paper}

Please note that where the full-text provided on Manchester Research Explorer is the Author Accepted Manuscript or Proof version this may differ from the final Published version. If citing, it is advised that you check and use the publisher's definitive version.

\section{General rights}

Copyright and moral rights for the publications made accessible in the Research Explorer are retained by the authors and/or other copyright owners and it is a condition of accessing publications that users recognise and abide by the legal requirements associated with these rights.

\section{Takedown policy}

If you believe that this document breaches copyright please refer to the University of Manchester's Takedown Procedures [http://man.ac.uk/04Y6Bo] or contact uml.scholarlycommunications@manchester.ac.uk providing relevant details, so we can investigate your claim.

\section{OPEN ACCESS}




\section{Accepted Manuscript}

Time-dependent spalling behavior of thermally grown oxide induced by room temperature interfacial deformation

B.Q. Xu, J.S. Jiang, Z.H. Zou, W.Z. Wang, X.F. Zhao, Y.Z. Liu, P. Xiao

PII: S0257-8972(17)31181-7

DOI: doi:10.1016/j.surfcoat.2017.11.037

Reference: SCT 22885

To appear in: Surface \& Coatings Technology

Received date: 22 August 2017

Revised date: 3 November 2017

Accepted date: 14 November 2017

Please cite this article as: B.Q. Xu, J.S. Jiang, Z.H. Zou, W.Z. Wang, X.F. Zhao, Y.Z. Liu, P. Xiao , Time-dependent spalling behavior of thermally grown oxide induced by room temperature interfacial deformation. The address for the corresponding author was captured as affiliation for all authors. Please check if appropriate. Sct(2017), doi:10.1016/ j.surfcoat.2017.11.037

This is a PDF file of an unedited manuscript that has been accepted for publication. As a service to our customers we are providing this early version of the manuscript. The manuscript will undergo copyediting, typesetting, and review of the resulting proof before it is published in its final form. Please note that during the production process errors may be discovered which could affect the content, and all legal disclaimers that apply to the journal pertain. 


\section{Time-dependent Spalling Behavior of Thermally Grown Oxide Induced by Room Temperature Interfacial Deformation}

B. Q. Xu ${ }^{1,2}$, J.S. Jiang ${ }^{2}$, Z. H. Zou ${ }^{1,2}$, W. Z. Wang ${ }^{2}$, X.F. Zhao ${ }^{1,2},{ }^{*}$ Y.Z. Liu $^{2}$ and P. Xiao ${ }^{3}$

${ }^{1 .}$ School of Materials Science and Engineering, Shanghai Jiao Tong University, Shanghai 200240, China

2. Gas Turbine Research Institute, Shanghai Jiao Tong University, Shanghai 200240, China

${ }^{3 .}$ School of Materials, University of Manchester, Grosvenor Street, Manchester M1 7HS, UK

*Corresponding author

Tel/Fax: +86-021-54742561.

Email: xiaofengzhao@sjtu.edu.cn 


\begin{abstract}
The room temperature spalling of oxide scale is an important phenomenon for the application of high temperature alloys or coatings. In this study, the mechanism of the time-dependent spalling behavior of the thermally grown oxide (TGO) formed on a Pt-diffused bond coat was investigated. To detect the interfacial deformation at room temperature, the surface roughness of the TGO was measured in situ as function of time immediately after cooling, which reflected the change of interfacial morphology. Finite element analysis was employed to simulate the deformation and crack nucleation at the interface. It was proposed that the room temperature plastic deformation could occur at the TGO/bond coat interface, leading to the crack nucleation. Furthermore, the effect of the interface geometry on the crack length was also studied. It was inferred that the time-dependent spalling behavior of the TGO might be associated with the room temperature deformation of the interface.
\end{abstract}

Keywords: Bond coat; Thermally grown oxide; Spallation; Deformation; Interface. 


\section{Introduction}

Many coatings and alloys operating at high temperature rely on the formation of a continuous and adherent thermally grown oxide (TGO) layer, usually alumina, for oxidation or corrosion protection [1-4]. One important application is the thermal barrier coatings (TBCs) designed for gas turbines, which typically comprises a metallic bond coat made of MCrAlY or platinum diffused nickel aluminide, on top of which is a ceramic top coat [2]. This multilayer system enables the superalloy components to operate at a much higher temperature than its melting point, and thereby improves the efficiency and the lifetime of engines. However, failure of TBCs from the TGO/bond coat interface is inevitable, which is driven by the residual stress in the TGO, and resisted by the interfacial toughness [5-14]. The current elasticity theory predicts that, the TGO stress attains to the maximum at the room temperature. The TBCs should spall immediately after cooling $[15,16]$. However, it is frequently observed that, for both the electron beam physical vapor deposited and air plasma sprayed TBCs, the spallation usually occurs after a period of time after cooling to the room temperature $[6,7,17]$. The incubation period varies from several hours to tens of days, or even months. This implies the time dependence spalling behavior is a universal phenomenon. However, this feature is not normally considered in the models that have been developed to describe buckling or spalling of compressed films and coatings $[16,18]$. In the usual mechanics descriptions $[16,19,20]$, spallation of the TBCs (or the TGOs) is considered as an instantaneous event associated with a mechanical bifurcation instability. Research into this phenomenon is critical for understanding the failure mechanisms both for TBCs and other oxide-substrate systems. However, in spite of its importance, few efforts have been made and the mechanism of this 
phenomenon is still not clear.

It has been envisaged that the time-dependent spalling behavior is associated with the moisture induced stress corrosion [21, 22]. The water vapor penetrates through the microcracks into the oxide/metal interface and initiates the decohesion. For example, the $\mathrm{TGO} /$ metal interface is affected by the presence of water vapor [23]. Tolpygo and Clarke investigated the spallation behavior of the alumina scale formed on $\mathrm{FeCrAl}$ alloy [6, 7]. It clearly demonstrated that the time-dependent spalling still occurs in purified nitrogen with zero humidity [7]. Therefore, the moisture induced stress corrosion is not a dominant factor. In addition, the stress in the oxide scale is not the sole reason for the spallation. For example, the TGO with a higher stress could have no or less spallation [6]. To explain this, they proposed that the spallation of the TGO is associated with the relaxation of the substrate [7]. This assumption, however, only focused on the cooling process and did not take into account of the deformation at room temperature. Indeed, the stress in the substrate induced by the TGO is much lower than its yielding strength so that the overall plastic deformation of the substrate at room temperature is negligible. To date, no reasonable explanation exists that can address the time-dependent spalling behavior of TBCs at room temperature.

Essentially, failure of TBCs or TGOs is associated with the out-of-plane tensile stress around the imperfection site (e.g., rumpling, wrinkle, etc.) at the interface [16]. The TGO stress redistributes at the wrinkled interface, inducing a stress concentration in the bond coat close to the interface. Once such local stress exceeds the yielding strength of the bond coat, plastic deformation occurs. Previous finite element analysis (FEA) indicated that, the stress at the 
undulation site can be up to several hundred $\mathrm{MPa}[24,25]$. Therefore, the interfacial deformation is highly possible to occur at room temperature. Because the TGO is rather stiff, when the deformation of TGO exceeds its elastic limit and cannot follow the deformation of the bond coat, cracks generate at the interface. Driven by such plastic deformation, the crack can grow with the time and buckling occurs once exceeding a critical radius [16]. This might be responsible for the time-dependent spalling behavior of the TBCs at the room temperature. Understanding this should help in designing optimal bond coat surface with enhanced TGO spallation resistance.

Therefore, the objective of this study is to investigate if the plastic deformation of the $\mathrm{TGO} /$ bond coat interface can occur at room temperature, to address the time-dependent behaviors of TBCs spalling. Since the TGO surface does not change at room temperature (except spalling or buckling), the surface roughness might reflect the deformation of the interface. Therefore, by measuring the TGO surface roughness, we can know the deformation of the interface. In this study, a surface profilometer will be employed to measure the surface roughness change, which has a nominal resolution in nanometer scale in vertical direction. FEA will also be used to simulate the stress distribution and deformation at the TGO/bond coat interface. A cohesive zone model characterized by a bilinear traction-separation law will be applied to investigate the interfacial cracking behavior, in order to understand the relationship between the interfacial geometry and the crack.

\section{Experiment}




\subsection{Sample preparation}

The sample used in this research was a platinum diffused $\gamma / \gamma^{\prime}$ bond coat on a CMSX-4 superalloy substrate ( $5 \mathrm{~mm}$ in thickness). It was prepared by electroplating a $7 \mu \mathrm{m}$ Pt onto the substrate, followed by a diffusion treatment at $1150^{\circ} \mathrm{C}$ in vacuum for 1 hour. This treatment produced a Pt- $\gamma / \gamma$ ' layer (about $25 \mu \mathrm{m}$ in thickness) on the surface of the substrate. To exclude the influence of top coat and have a better observation of the surface microstructure, no YSZ layer was deposited on the sample. The specimens were cut to $10 \mathrm{~mm} \times 10 \mathrm{~mm}$ plates and isothermally oxidized at $1150^{\circ} \mathrm{C}$ for 40 hours in a laboratory chamber furnace, with a heating rate of $10^{\circ} \mathrm{C} / \mathrm{min}$. After required exposure, the specimens were withdrawn from the furnace and cooled to the room temperature in air at a rough rate of $\sim 200^{\circ} \mathrm{C} / \mathrm{min}$, which was estimated by temperature drop/cooling time. Then the surface roughness of the TGO was recorded as a function of time at room temperature, immediately after cooling.

\subsection{Surface roughness measurement}

The surface roughness of the TGO was measured as soon as the oxidized samples were cooled to the room temperature, using an optical profilometer (Zygo Corporation). The profilometer provided a digital image in the form of height, $\mathrm{z}$, as a function of lateral position, $\mathrm{x}$ and $\mathrm{y}$. At each stage, images of the same area were recorded so that the behavior of the identical regions of the surface could be compared. The measurement was performed using a $\times 10$ lens (Nikon Corporation) and the scanned area was $832 \times 832 \mu \mathrm{m}^{2}$. The in-plane resolution of the measurements was $1024 \times 1024$ pixels (corresponding to about $0.8 \mu \mathrm{m}$ ). The digital images are in color, with individual colors corresponding to different heights of the surface, as shown 
in Fig. 1a.

The surface roughness, Sa refers to the arithmetic mean of the absolute ordinate values within a sampling area:

$$
\mathrm{Sa}=\frac{1}{\mathrm{MN}} \sum_{\mathrm{i}=1}^{\mathrm{M}} \sum_{\mathrm{j}=1}^{\mathrm{N}}\left|\mathrm{Z}\left(\mathrm{x}_{\mathrm{i}}, \mathrm{y}_{\mathrm{j}}\right)\right|
$$

where the scanned surface area is defined by $\mathrm{M}$ pixels in the $\mathrm{x}$-axis and $\mathrm{N}$ pixels in the $\mathrm{y}$-axis, and $\mathrm{Z}$ means the height of each pixel.

\subsection{TGO stress measurement}

The residual stresses in the TGO were measured in situ at room temperature using photoluminescence piezospectroscopy, PLPS (LabRAM HR Evolution, HORIBA). Spectra were collected in a backscattering geometry using an YAG source $(\lambda=532 \mathrm{~nm})$ and a cooled CCD detector. For mapping the stress distribution in the TGO layers, the incident beam was focused to a spot of approximately $3 \mu \mathrm{m}$ on the sample surface by means of a $10.6 \mathrm{~mm}$ long working distance objective lens (Olympus). The focused spot was scanned over the specimen by moving the motorized stage in steps of a predetermined length and at each step position a spectrum of R1 and R2 lines [26] was recorded. The residual stress was measured as function of time immediately after cooling to the room temperature. Data were recorded every 5 minutes by means of Swift Mode, leading to an uncertainty on the spallation of \pm 5 minutes. Collected spectra were fit using Gaussian - Lorentzian functions in a commercial software (Labspec 6, HORIBA Corporation).

The TGO stress was estimated from the peak shift with respect to the unstrained sapphire 
reference by assuming a state of equibiaxial plane stress and a random distribution of the crystallographic texture in the TGO. The frequency shift can be related to the stress by the equation [27]:

$$
\Delta \mathrm{v}=5.07\left(\mathrm{~cm}^{-1} \mathrm{GPa}^{-1}\right) \sigma,
$$

where $\Delta \mathrm{v}$ is the frequency shift of the R2 line and $\sigma$ is the biaxial stress in the TGO. Since the scale length of the roughness (e.g., the height or the wavelength) is comparable to the TGO thickness, the stress is not strictly biaxial. Therefore, the TGO stress measured by PLPS might have error. In this study, we used this technique to evaluate the TGO stress evolution at specific regions (e.g., interface deformed or spalled regions). Although the stress value might not be accurate, the trend of the stress is still valid since the same region was measured.

\subsection{Microstructure characterization}

The TGO surface morphology was observed using an optical microscope (U-LH100-3, Olympus). The spalled and the intact region were distinguished by the contrast, since the delamination regions were brighter. The cross-section structure of the Pt- $\gamma / \gamma^{\prime}$ samples was observed using a scanning electron microscope (SEM, FEI Quanta 200).

\subsection{Finite element analysis of the interface}

In order to simulate the interfacial deformation and crack initiation, a cohesive zone model characterized by a bilinear traction-separation law was adopted using a commercial FEA package (ABAQUS 6.13). The cohesive law was built into FEA by using cohesive elements which were inserted between TGO and the bond coat. It was assumed that the cohesive 
elements satisfied linear elasticity prior to damage, and damage initiated once a certain initiation criterion is reached. The details are as follows:

(i) For the sake of simplicity, the interface was set with a sinusoidal shape and uniform thickness. The thickness of the bond coat and the substrate were set as $\sim 50 \mu \mathrm{m}$ and $4000 \mu \mathrm{m}$, respectively. The interface vertical position of the sinusoidal curve was expressed as: $y(x)=A \cdot \sin (2 \pi x / L)$. The amplitude $(A)$, the wavelength (L) and the TGO thickness were obtained through observations of the cross-section morphology of the sample.

(ii) The displacement in $\mathrm{x}$ direction of the left edge was set to be zero to obtain a symmetric condition, while the periodic boundary condition was imposed on the right edge by the multi-point constraint method [28]. This method constrained the affected edge to remain plane and vertical, but it was allowed to move in the $\mathrm{x}$ direction. The displacement in y direction of the substrate bottom was set to be zero. The top edge of the TGO was free from any constraints.

(iii) It was assumed that the temperature of the whole system was spatially uniform and decreased linearly from $1150^{\circ} \mathrm{C}$ to $20^{\circ} \mathrm{C}$ in 3 minutes. The stress and deformation resulting from the TGO growth were not considered since the TGO growth was negligible during cooling [20]. No external force was imposed on the TBC system.

(iv) The four-node interface cohesive elements (COH2D4) were set between the TGO and the bond coat to imitate the crack. In other words, the crack is limited to initiate and propagate along the interface. The four-node generalized plane strain elements (CPEG4T) were adopted to mesh the TGO, the bond coat and the substrate. The mesh 
size was graded in the thickness direction (y direction) with finer meshes near the interface. The minimum mesh size around the interface was about $0.05 \mu \mathrm{m}$, and the thickness of the cohesive elements was negligibly small.

(v) Each layer was taken to be homogeneous and isotropic. The linear elastic constitutive relationship was employed for the TGO, while the ideal elastoplastic model was chosen for the bond coat. The crack initiates (presented by element deletion) once the damage values reach 1 and the energy release rate reach their corresponding critical values $[29,30]$. The cohesive zone model applied in this study was characterized by a bilinear traction-separation law [29] expressed as

$$
\sigma= \begin{cases}K \delta, & \delta \leq \delta_{0} \\ (1-D) K \delta, & \delta_{0}<\delta<\delta_{f} \\ 0, & \delta \geq \delta_{f}\end{cases}
$$

and

$$
D= \begin{cases}0, & \delta \leq \delta_{0} \\ \frac{\delta_{f}\left(\delta-\delta_{0}\right)}{\delta\left(\delta_{f}-\delta_{0}\right)}, & \delta_{0}<\delta<\delta_{f} \\ 1, & \delta \geq \delta_{f}\end{cases}
$$

where $\sigma$ is the stress, $\delta$ the displacement, $\delta_{0}$ the critical opening displacement, $\delta_{f}$ the fracture displacement, $\mathrm{D}$ the damage variable ranging from 0 to 1 , and $\mathrm{K}$ the initial interfacial stiffness. The critical fracture energy was expressed as

$$
\mathrm{G}_{\mathrm{c}}=\frac{1}{2} \sigma_{0} \delta_{f}
$$

where $\sigma_{0}$ is the interfacial strength. Other mechanical parameters used in this simulation were listed in Table 1. 
(vi) The following maximum nominal stress criterion was applied:

$$
\max \left\{\frac{\sigma_{\mathrm{n}}}{\sigma_{\mathrm{n}}^{0}}, \frac{\sigma_{\mathrm{s}}}{\sigma_{\mathrm{s}}^{0}}\right\}=1
$$

where $\sigma_{\mathrm{n}}^{0}$ and $\sigma_{\mathrm{s}}^{0}$ are the interfacial critical stresses in opening and sliding modes respectively.

The dependence of the mixed-mode fracture process was defined by the following criterion:

$$
\frac{\mathrm{G}_{\mathrm{n}}}{\mathrm{G}_{\mathrm{n}}^{\mathrm{c}}}+\frac{\mathrm{G}_{\mathrm{s}}}{\mathrm{G}_{\mathrm{s}}^{\mathrm{c}}}=1
$$

where $G_{n}^{c}$ and $G_{s}^{c}$ are the critical energy release rates in mode I and mode II respectively. In this simulation, the following fracture data [30-32] were used for TGO/BC interface: $\mathrm{G}_{\mathrm{n}}^{\mathrm{c}}=20 \mathrm{Jm}^{-2}, \mathrm{G}_{\mathrm{s}}^{\mathrm{c}}=60 \mathrm{Jm}^{-2}, \sigma_{\mathrm{n}}^{0}=200 \mathrm{MPa}, \sigma_{\mathrm{s}}^{0}=100 \mathrm{MPa}$, $\mathrm{K}=200 \mathrm{GPa}$.

\section{Results}

\subsection{Microstructure characterization}

Fig. $1 \mathrm{~b}$ presents the cross-sectional microstructure of the $\gamma / \gamma^{\prime}$ bond coat after oxidation of 40 hours at $1150^{\circ} \mathrm{C}$. After oxidation, a thin layer of TGO (about $4 \mu \mathrm{m}$ thick) formed on the surface. The bond coat consisted of two phases. The bright areas were the $\gamma^{\prime}-\mathrm{Ni}_{3} \mathrm{Al}$ phase, while the dark areas were the $\gamma$-Ni phase. Both phases were enriched with platinum. The 
surface morphologies of the TGO were taken with a tilt angle $63^{\circ}$, as shown in Fig. 2. The TGO surface was wrinkled (a roughness of about $2 \mu \mathrm{m}$ ) after oxidation compared to the as-received sample (a roughness of about $0.88 \mu \mathrm{m}$ ). The spallation of the TGO shows a typical time-dependent behavior at the temperature, i.e., the TGO is intact immediately after cooling, but local TGO spalling gradually appears and grows with the time (as detailed in next part).

3.2 Evolution of the surface morphology with the dwelling time

To understand the time-dependent behavior of the surface roughness at room temperature, the surface morphology of the TGO was recorded as a function of the dwelling time (up to 24 hours). Fig. 3 presents the typical spalling process of the TGO. Immediately after cooling to the room temperature, there was no TGO spallation (Fig. 3a). After 30 minutes, local spallation occurred (indicated by arrows in Fig. 3b). No new spallation appeared until 2 hours (Fig. 3d). After that, the surface of the TGO remained stable with further increase of the dwelling time.

\subsection{Surface roughness evolution}

Since the change of the TGO surface is related to the change of the interface, we used the surface roughness measurement to study the deformation of the interface. Fig. 4 presents the evolution of the TGO surface roughness as a function of the dwelling time at room temperature. The curve could be divided into four stages:

(i) In the first stage (0 - $30 \mathrm{~min})$, the surface roughness decreased with the time, attributed 
to the formation of local TGO spallation (as will be discussed in Section 4.1).

(ii) In the second stage (30 - $200 \mathrm{~min})$, the surface roughness increased with the dwelling time and reached to a local maximum. In this stage, two important phenomena were also observed. First, the amplitude of the wrinkle increased. This suggested the surface underwent stress relaxation through the elongation of the TGO. Second, when the roughness reached to maximum, the separation between the TGO and the bond coat started to appear, usually at the peaks of the wrinkle. This suggested the localized tensile stress at the $\mathrm{TGO} /$ bond coat interface was large enough to initiate the interfacial cracks at the peaks. Since the TGO topology could not change at room temperature, the increase of the TGO roughness was induced by the deformation of the bond coat at the interface.

(iii) In the third stage (200 - $720 \mathrm{~min}$ ), the surface roughness decreased with time, which could be attributed to the formation of new local TGO spallation like the first stage.

(iv) In the final stage (after $720 \mathrm{~min}$ ), the surface roughness became stable. Although the total change of the surface roughness was about $0.4 \mu \mathrm{m}$, the result is reliable and reproducible because the resolution of the profilometer is higher than $0.01 \mu \mathrm{m}$.

To get more information, we analyzed the roughness change at the spalled region. Fig.5 showed the height change at the spalled region compared with the reference region (i.e. no TGO spalled). The un-spalled region can be easily differentiated from the spalled region in the optical microscope due to the image contrast. The height of the reference area might change as a function of time, but it is much smaller compared with the spalled area. Therefore, it can be used for comparison. As can be seen in Fig. 5, the height of the measure site first 
increased by up to $4 \mu \mathrm{m}$. At this stage, the TGO was still intact with the bond coat (judged by image contrast). Therefore, the height increase could only be attributed to the interfacial deformation, i.e., increase of the wrinkle amplitude. After that, the TGO started to spall from the bond coat, leading to a sudden drop (about $4.6 \mu \mathrm{m}$ ) in the height. The value was close to the TGO thickness (about $4 \mu \mathrm{m}$ in this study). This suggested that the initial increase in the height was mainly induced by the deformation of the bond coat at the interface (amplitude increase), not the buckling of the TGO. Otherwise, the drop should be much larger than the TGO thickness. This result provided the first ever evidence to show the TGO/bond coat interface can deform at the room temperature. After drop, the $\mathrm{Z}$ value became constant. The change of the height in Fig. 5 exhibited the same trend as the change of the TGO roughness (Fig. 4), which clearly suggested that the increase of the TGO roughness was caused by the interfacial deformation, and the decrease of the TGO roughness was caused by the TGO spallation.

\subsection{TGO stress evolution and distribution}

Since the deformation of the bond coat at the interface would change the stress in the TGO, especially near the wrinkled sites, the TGO stress was further examined to understand the time-dependent spalling behavior. Fig. 6a shows the maps of the TGO stresses at different moments. The TGO stresses can be distinguished by colors. The red areas represent the separated TGO with released biaxial stress. New TGO separation formed during 255 to 285 minutes after the thermal treatment was observed (rectangle in the figure). Fig. $6 \mathrm{~b}$ plots the evolution of the average stress in those areas with the time. At the beginning, the TGO stress 
was about -3.5 GPa. After four hours, the TGO stress decreased from -3.5 GPa to -1.4 GPa.

To verify the relationship between the stress evolution and the TGO delamination, a two-dimensional FE simulation was performed. Fig. 7 shows the schematic of the TGO buckled from the bond coat. The TGO separation is approximated as a spherical shape. Based on the experimental observation, the maximum height of the buckling (h) and the diameter of the buckling $\left(\mathrm{B}_{0}\right)$ are taken as $4 \mu \mathrm{m}$ and $80 \mu \mathrm{m}$, respectively. The stress relaxation $\Delta \sigma$ can be deduced by Hooke's law:

$$
\Delta \sigma=E\left(B-B_{0}\right) / B
$$

where B is the length of the buckled TGO, E the TGO modulus (400 GPa). Using Eq. (7), the corresponding stress relaxation is about $2.6 \mathrm{GPa}$. This value is in general agreement with the experimental value 2.1 GPa (Fig. 6b). Thus, the decrease of the TGO stress implied that the TGO was detached from the bond coat, but not spalled away (the stress would become zero if the TGO totally spalled).

After TGO separation, the TGO stress redistributed. Fig. 6c shows the stress distribution around the separated site. The lowest stress existed at the center of the separation (at the peak region of the wrinkle). The highest stress existed at the rim of the separation (at the valley region of the wrinkle). This observation is in agreement with previous works by Tolpygo and Clarke, in which the peak exhibited a lower stress, while the valley exhibited a higher stress [11].

The evolution of TGO stress demonstrated that the TGO spallation was not finished 
immediately after cooling. The stress in the TGO kept changing as a function of time, which was related to the interface deformation at room temperature.

3.5 Numerical simulation of the interfacial deformation and crack

Conventional techniques fail to detect the stress distribution in the bond coat near the interface. Thus, FEA was employed to simulate the interfacial stress and deformation. Based on the typical cross-section morphology of the interface (Fig. 1b), the dimension parameters were set as follows: the TGO thickness $\mathrm{h}=4 \mu \mathrm{m}$, the wavelength $\mathrm{L}=10 \mu \mathrm{m}$ and the amplitude $\mathrm{A}=0.95 \mu \mathrm{m}$, as shown in Fig. 8a. The typical computational mesh in the TGO and out layer of the bond coat was shown in Fig. 8b. Three circumstances were considered: (i) the bond coat with elastic deformation, (ii) the bond coat with both elastic and plastic deformation, (iii) the bond coat with both elastic and plastic deformation, with the addition of the interfacial crack.

The first case was used to confirm whether the bond coat could deform under the residual stress in the TGO. Fig. 9 shows the Mises distribution at the interface in elastic regime, without considering the plastic deformation or the interface crack. Since the TGO thickness is nearly $1 / 1000$ of the metallic substrate, the overall stress in the bond coat is only several MPa. However, close to the interface, the bond coat stress is significantly higher. Fig. $9 \mathrm{~b}$ presented the stress distribution of the bond coat at the interface. The Mises stress in the bond coat reached $3.5 \mathrm{GPa}$, which was much higher than its yielding strength at room temperature (426 MPa [13]). Thus, local plastic deformation in the bond coat (close to the interface) could occur at the room temperature. 
The second case was used to explain the stress distribution around the interface to see whether the stress was large enough to induce crack. Fig. 10 shows the stress components of the bond coat with both elastic and plastic deformation, without considering the interface crack. Stress concentrated at the peak and valley of TGO (Fig. 10a). The cracks tended to form at the peaks because the peaks at the interface suffered compression in the $\mathrm{x}$ direction (Fig. 10b) and tension in the y direction (Fig. 10c and d). To have a better understanding, the normal stress distribution of the bond coat along the interface was shown in Fig. 11. In the case without crack, the highest normal stress (415 MPa) occurred at the peak of the interface. The stress was higher than the interfacial strength (200 MPa in present model), which was large enough to induce crack.

The third case was used to see the effect of interfacial stress on the crack nucleation. Fig. 12 shows the stress distribution of the bond coat with elastic, plastic deformation and the formation of the interfacial crack. Compared to Fig. 10, the distribution of $\sigma_{y}$ in the bond coat changed apparently after cracking (Fig. 12c and d). From Fig. 10d, 11 and 12d, it can be seen that with the crack propagating at the interface, the highest tensile stress moved along the interface to the vicinity of the crack tips. Such stress distribution is in general agreement with the previous investigations $[11,16]$.

The numerical simulation clearly confirmed that local plastic deformation could occur in the bond coat at the room temperature. A crack could nucleate at the peak of the wrinkle site where stress concentrated. The tensile stresses normal to the interface concentrated at the crack tips, leading to the crack propagation. 


\section{Discussion}

4.1 Understanding on the TGO roughness change

The evolution of the surface roughness at room temperature is a surprising finding in this work. Since the TGO surface does not change at room temperature (except spalling or buckling), the evolution of the surface roughness might reflect the deformation of the TGO/bond coat interface. The interfacial cracks might be associated with the local plastic deformation of the interface. Since the room temperature plastic deformation rate of the bond coat is quite low, the spalling of the oxide exhibited a typical time-dependent behavior. The deformation takes a period, which is called incubation time. During the incubation time, the interfacial cracks nucleate at the peaks of the undulation and propagate along the interface.

Once the crack length reaches tens of micrometers, the TGO will separate from the bond coat. If the TGO separation is approximated as a spherical shape, the separation size is in agreement with the theoretical prediction $[18,33]$ for buckling of a compressively stressed thin film, namely that the buckle diameter [11], $a_{c}$, is given by

$$
a_{c}=g h \sqrt{E / \sigma_{c}},
$$

where $g$ is a geometric parameter ( $g \approx 2.2$ for an axisymmetric buckle), h the TGO thickness, E the elastic modulus of the TGO, and $\sigma_{c}$ the biaxial compressive stress. Substituting in appropriate values $\left(\mathrm{h}=4 \mu \mathrm{m}, \sigma_{c}=4 \mathrm{GPa}\right.$ and $\left.\mathrm{E}=400 \mathrm{GPa}\right)$, the predicted buckle size is about 88 
$\mu \mathrm{m}$, a value similar to the experimental observations (Fig. 3 and 6a).

This form of failure is accompanied by distinct cracks through the TGO at the periphery of the buckle, a displacement away from the bond coat surface [11]. The observations show that it occurs at random locations on the bond coat surface. After the TGO spallation from the bond coat, the local roughness decreased by several microns (e.g., $4.6 \mu \mathrm{m}$ in this study), mainly dependent on the TGO thickness. Consequently, the surface roughness of the whole TGO surface decreased.

In summary, the increase of the surface roughness is possibly induced by the deformation of the TGO/bond coat interface, while the decrease is the result of the local TGO spallation. Identical behavior was also observed in other bond coat systems, e.g. NiCoCrAlY and NiCrAlY bond coats on Hastelloy substrates (see supplementary materials), which proved that the time-dependent spalling of the TGO is universal phenomenon for many other high temperature coatings.

\subsection{Interfacial deformation induced by TGO stress redistribution}

To understand the deformation of the bond coat at the interface, the residual stress in the bond coat is required a detailed analysis. The residual stress in the TGO is mainly generated by the thermal misfit between the TGO and the substrate during the cooling. At high cooling rates, the strain relaxation is negligible and large stress is preserved [6]. Without considering plastic deformation, the Mises stress in the outer layer of the bond coat at wrinkled site is up to 3.7 GPa (Fig. 9b) according to the FEA results. Since the yielding strength of the bond coat at 
room temperature is $426 \mathrm{MPa}$ [13], the surface layer of the bond coat undertakes stress relaxation through plastic deformation.

As the bond coat at the interface deforms, the ratio of the rumpling amplitude and wavelength (A/L) increases. Tensile stress and compressive stress concentrates at the peak and valley, respectively. The tensile stress perpendicular to the TGO/bond coat interface initiates micro crack once the strain energy release exceeds the fracture resistance [33]. Thereafter, tensile stress concentrates at the crack tip (Fig. 11 and 12d), impelling the crack to propagate along the interface.

In short, the local stress in the bond coat is large enough to induce deformation. Tensile stresses develop at the peaks of the $\mathrm{TGO} /$ bond coat interface, initializing the cracks. Thereafter, the stresses concentrated at the crack tips impel the propagation of the cracks. As will be discussed below, the crack initiation and propagation are highly dependent on the interface geometry.

\subsection{Effect of interface geometry on the crack nucleation}

Grit blasting is usually employed in practice to generate a rough bond coat surface for the TBC adhesion, which is a critical factor for the TBCs lifetime. To identify the optimal surface roughness, the interface morphology on the crack initiation and propagation is also investigated by FEA. Assuming a sinusoidal shape, the interface morphology is described by the wavelength (L) and the amplitude (A). Fig. 13 shows the relationship between the interfacial geometry and the crack length. Two features can be drawn from the figure. 
First, there exists a critical value for the amplitude that may induce interfacial crack. Above this value, the interface separation is energetically favored. In presented study, the TGO thickness is $4 \mu \mathrm{m}$, the TGO stress is $-3.5 \mathrm{GPa}$, and the critical amplitude is about $0.9 \mu \mathrm{m}$. It indicates that a smooth surface with low amplitude should be beneficial for the TGO spallation resistance at room temperature. However, since the TGO formed on a smooth surface usually has a larger residual stress than that formed on a rough surface (due to less stress relaxation), there should exist an optimal value for the amplitude and wavelength.

Second, the length of the interfacial crack depends on the wavelength and amplitude of the wrinkle. For a given amplitude, the crack length increases with the wavelength. For a given wavelength, the crack length increases with the amplitude. This is because the larger amplitude induces higher tensile stress at the peak region, accelerating the interfacial crack initiation. This is consistent with previous reports [34]. For a given amplitude, the larger wavelength facilitates the interfacial crack propagation, leading to a longer crack. This result is different with the previous model developed by Evans and He [34]. They predicted that the tensile stress perpendicular to the interface is proportional to $\mathrm{A} / \mathrm{L}$. Thus, the stress acted on a longer wavelength should be lower, which is not favorable for cracks. The cause of the discrepancy might be that Evan's model is a static model, which only considers the stress but not the crack propagation.

4.4 Understanding on the TGO spallation at the room temperature

Based on above discussion, the TGO spallation process after cooling to the room temperature can be understood as follows: 
After cooling, the TGO was in compressive stress, which arises from the thermal mismatch between the TGO and the substrate, and the TGO growth strain at oxidation temperature [15]. As the interface between the TGO and the bond coat is not strictly smooth (either from the non-uniform TGO growth or from the grit blasting), the residual stress in the TGO redistributes at the wrinkled interface and generates tensile stress normal to the interface. The cracks first nucleate at the peaks and coalesce to form spallation. This mechanism has been extensively investigated by Evans et al. and well accepted by TBCs community [15]. The contribution of this study is that we find there exists a critical wrinkle amplitude. The cracks only generate when the amplitude exceeds this critical value.

In the dwelling time, the stresses concentrated at wrinkle sites might lead to local plastic deformation at the surface layer of the bond coat, resulting in an increase of the amplitude. When the amplitude reaches the critical value, interfacial crack nucleates at the peak. The crack propagates with further deformation and coalesces. Therefore, the spallation of the TGO at room temperature exhibits a time-dependent behavior. In present study, the theoretical critical buckling size is about $80 \mu \mathrm{m}$. For buckling to occur, it requires a wrinkle cluster larger than this size, with all amplitudes higher than $0.9 \mu \mathrm{m}$ (Fig. 13). This is because the amplitude lower than this value would not generate interfacial cracks, and thus no TGO spallation. This means the TGO spallation is not only time dependent, but also area selective.

As generally believed, the metal is not able to creep at room temperature. To our best of knowledge, little attempt has been made on the theoretical analysis of room temperature deformation. By contrast, lot of efforts have been put on the study of high temperature creep 
of the coatings $[12,35]$. The deformation of the coatings and the sequent crack formation were attributed to the high temperature creep. However, our experimental results imply that the coatings do undergo time dependent deformation at room temperature. Moreover, the time dependence behavior is suggested to be induced by the deformation of the bond coat.

\section{Conclusion}

In this work, the room temperature spalling behavior of the TGO formed on a Pt-diffused bond coat was investigated. The spalling of the TGO at room temperature exhibited a typical time-dependent behavior, i.e., the TGO is adherent to the bond coat immediately after cooling, but gradually spalls with an increase of dwelling time, varying from several hours to days.

The in-situ surface roughness measurement was employed to evaluate the deformation of the bond coat at the interface. It was found that the increase in the TGO roughness was induced by the interfacial deformation at the room temperature, and the decrease in the roughness was induced by the local spallation of the TGO.

A two-dimensional FE model was employed to simulate the interfacial deformation and the crack nucleation. The numerical results confirmed that the residual stress concentrated at the wrinkle sites could generate interfacial deformation at room temperature, leading to an increase of the amplitude. Since the TGO is a rigid body at room temperature, the cracks nucleate at the interface when the bond coat deforms as time increases. Therefore, the time-dependent spallation of the TGO could be attributed to the interface deformation at room 
temperature, rather than the moisture induced failure.

In addition, the effect of interface geometry on the growth of cracks has been studied by FEA. For a given wrinkle amplitude, the crack length increases with the wavelength. For a given wavelength, the crack length increases with the amplitude. There exists a critical amplitude for the spontaneous interfacial crack at room temperature. In present study ( $4 \mu \mathrm{m}$ thick TGO), the critical amplitude for the crack nucleation is about $0.9 \mu \mathrm{m}$. This indicates that the interfacial geometry is a critical factor to affect the room temperature spalling of the TGO. 


\section{Acknowledgement}

The authors would thank the financial support from Institute of Gas Turbines, Shanghai Jiao

Tong University. 


\section{References}

[1] N. R. Lindblad, Oxidation of Matals. 1 (1969) 143.

[2] D. R. Clarke and C. G. Levi, Annual Review of Materials Research. 33 (2003) 383.

[3] N. P. Padture, M. Gell and E. H. Jordan, Science. 296 (2002) 280.

[4] M. J. Stiger, N. M. Yanar, M. G. Topping, F. S. Pettit and G. H. Meier, Zeitschrift Fur Metallkunde. 90 (1999) 1069.

[5] K. Vaidyanathan, E. H. Jordan and M. Gell, Acta Materialia. 52 (2004) 1107.

[6] V. K. Tolpygo and D. R. Clarke, Materials Science and Engineering: A. 278 (2000) 142.

[7] V. K. Tolpygo and D. R. Clarke, Materials Science and Engineering: A. 278 (2000) 151.

[8] V. K. Tolpygo and D. R. Clarke, Acta Materialia. 46 (1998) 5153.

[9] K. W. Schlichting, N. P. Padture, E. H. Jordan and M. Gell, Materials Science and Engineering: A. 342 (2003) 120.

[10]L. T. Wu, R. T. Wu, X. Zhao and P. Xiao, Materials Science and Engineering: A. 594 (2014) 193.

[11] V. K. Tolpygo and D. R. Clarke, Acta Materialia. 46 (1998) 5167.

[12] V. K. Tolpygo and D. R. Clarke, Acta Materialia. 52 (2004) 5115.

[13]J. Cheng, E. H. Jordan, B. Barber and M. Gell, Acta Materialia. 46 (1998) 5839.

[14]G. Parry, A. G. Evans and J. W. Hutchinson, Comptes Rendus Mécanique. 336 (2008) 224.

[15]A. G. Evans, D. R. Mumm, J. W. Hutchinson, G. H. Meier and F. S. Pettit, Progress in Materials Science. 46 (2001) 505.

[16]A. G. Evans and J. W. Hutchinson, International Journal of Solids \& Structures. 20 (1984) 455.

[17]C. Zhu, X. Zhao, Y. Chen, Y. Zhao, P. Xiao, I. S. Molchan and G. E. Thompson, Oxidation of Metals. 85 (2016) 391.

[18] M. D. Thouless, J. W. Hutchinson and E. G. Liniger, Acta Metallurgica Et Materialia. 40 (1992) 2639.

[19] A. A. Abdallah, D. Kozodaev, P. C. P. Bouten, J. M. J. D. Toonder and G. D. With, Fracture of Nano \& Engineering Materials \& Structures. (2006) 77.

[20]M. Y. He, A. G. Evans and J. W. Hutchinson, Physica Status Solidi. 245 (1998) 168.

[21]M. R. Turner and A. G. Evans, Acta Materialia. 44 (1996) 863.

[22]I. E. Reimanis, B. J. Dalgleish and A. G. Evans, Acta Metallurgica Et Materialia. 39 (1991) 3133.

[23]F. Gaudette, S. Suresh, A. G. Evans, G. Dehm and M. Rühle, Acta Materialia. 45 (1997) 3503.

[24]D. S. Balint, T. Xu, J. W. Hutchinson and A. G. Evans, Acta Materialia. 54 (2006) 1815.

[25] V. Maurel, L. Rémy, M. Harvey, H. T. du Montcel and A. Koster, Surface and Coatings Technology. 215 (2013) 52.

[26]J. He and D. R. Clarke, Journal of the American Ceramic Society. 78 (1995) 1347.

[27]A. Selcuk and A. Atkinson, Materials Science and Engineering: A. 335 (2002) 147.

[28]M. Ranjbar-Far, J. Absi, G. Mariaux and F. Dubois, Materials \& Design. 31 (2010) 772. 
[29]A. Needleman, Journal of the Mechanics \& Physics of Solids. 38 (1990) 289.

[30] M. Białas, Surface and Coatings Technology. 202 (2008) 6002.

[31] T. Xu, M. Y. He and A. G. Evans, Acta Materialia. 51 (2003) 3807.

[32] M. Y. He, A. G. Evans and J. W. Hutchinson, Acta Materialia. 48 (2000) 2593.

[33]D. R. Clarke and W. Pompe, Acta Materialia. 47 (1999) 1749.

[34]A. G. Evans, M. Y. He and J. W. Hutchinson, Acta Materialia. 45 (1997) 3543.

[35]D. Balint and J. Hutchinson, Journal of the Mechanics and Physics of Solids. 53 (2005) 949. 


\section{Figure captions}

Fig. 1. (a) Three-dimensional image of the wrinkled TGO surface measured by the optical profilometer. (b) Cross sectional image of the Pt- $\gamma / \gamma^{\prime}$ sample after oxidation. The thicknesses of the TGO and the bond coat are about $4 \mu \mathrm{m}$ and $50 \mu \mathrm{m}$, respectively.

Fig. 2. Surface morphology of the bond coat (a) before and (b) after oxidation. The surface roughness before and after oxidation are about $0.88 \mu \mathrm{m}$ and $2 \mu \mathrm{m}$, respectively.

Fig. 3. The spallation process of the TGO at the room temperature immediately after cooling (a) 0min, (b) 30min, (c) 50min, (d) $2 \mathrm{~h}$ and (e) 24h. Arrows indicate the newly formed TGO separations.

Fig. 4. Evolution of the surface roughness vs. the dwelling time at room temperature. The uncertainty mainly comes from the different image processing parameters such as void filling. The inset is a magnified view of the initial stage with a logarithmic coordinate.

Fig. 5. The curve refers to the height change of the TGO surface at a specific region as a function of time at room temperature. The specific region and reference area are indicated in the top right inset.

Fig. 6. (a) The TGO stress maps at different moments after cooling. (b) The plot of the 
average TGO stress vs. time at region where TGO separated from the bond coat. The uncertainty refers to the stress distribution in the analyzed region. (c) The TGO stress distribution around the separated region. The analyzed region is indicated in the inset with the same scale bar as that in (a).

Fig. 7. Schematic illustration of the TGO buckled from the bond coat.

Fig. 8. (a) Schematic illustration of an idealized sinusoidal geometry and the unit of the simulation. (b) Mesh in the TGO and out layer of the bond coat applied to the simulation.

Fig. 9. Stress distribution in the case of the bond coat with elastic deformation, without considering the interface crack: (a) the Mises stress in the TGO; (b) the Mises stress in the bond coat.

Fig. 10. Stress distribution in the case of the bond coat with both elastic and plastic deformation, without considering the interface crack: (a) the Mises stress in the TGO; (b) the TGO stress in $\mathrm{x}$ direction; (c) the TGO stress in y direction; (d) the bond coat stress in $\mathrm{y}$ direction.

Fig. 11. Normal stress distribution of the bond coat along the interface with and without interfacial crack. 
Fig. 12. Stress distribution in the case of the bond coat with both elastic and plastic deformation, with the addition of the interfacial crack: (a) the Mises stress in the TGO; (b) the TGO stress in $\mathrm{x}$ direction (the cohesive zone has no value in $\mathrm{x}$ direction); (c) the TGO stress in y direction; (d) the bond coat stress in y direction.

Fig. 13. Interfacial crack length as a function of the amplitude (A) and the wavelength (L). The TGO thickness is set as $4 \mu \mathrm{m}$ based on the experimental observation in this study. 


\section{Table caption}

Table 1. The material parameters used in the FEA simulation [13, 30]. 
Table

Table 1

\begin{tabular}{|c|c|c|c|c|c|}
\hline & $\begin{array}{l}\text { Temperature } \\
\mathbf{T}\left({ }^{\circ} \mathrm{C}\right)\end{array}$ & $\begin{array}{l}\text { Young's } \\
\text { modulus } \\
\text { E (GPa) }\end{array}$ & $\begin{array}{l}\text { Poisson's } \\
\text { ratio } \\
v\end{array}$ & $\begin{array}{l}\text { Thermal } \\
\text { expansion } \\
\alpha \times 10^{-6} \\
\left({ }^{\circ} \mathrm{C}\right)\end{array}$ & $\begin{array}{l}\text { Yielding } \\
\text { strength } \\
\sigma_{s}(\mathrm{MPa})\end{array}$ \\
\hline TGO & $\begin{array}{l}25 \\
200 \\
400 \\
800 \\
1100\end{array}$ & $\begin{array}{l}400 \\
390 \\
380 \\
355 \\
320\end{array}$ & 0.27 & $\begin{array}{l}5.1 \\
5.1 \\
5.1 \\
5.1 \\
5.1\end{array}$ & I \\
\hline BC & $\begin{array}{l}25 \\
200 \\
400 \\
800 \\
1100\end{array}$ & $\begin{array}{l}200 \\
190 \\
175 \\
145 \\
120\end{array}$ & 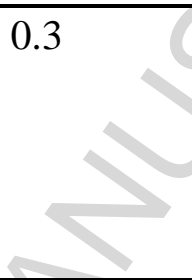 & $\begin{array}{l}12.3 \\
14.2 \\
15.2 \\
16.3 \\
17.6\end{array}$ & $\begin{array}{l}426 \\
412 \\
396 \\
284 \\
114\end{array}$ \\
\hline $\begin{array}{l}\text { Substrat } \\
\text { e }\end{array}$ & $\begin{array}{l}20 \\
220 \\
420 \\
620 \\
820 \\
1020\end{array}$ & $\begin{array}{l}123 \\
115 \\
108 \\
100 \\
92 \\
84\end{array}$ & $\begin{array}{l}0.36 \\
0.37 \\
0.37 \\
0.37 \\
0.38 \\
0.38\end{array}$ & $\begin{array}{l}12 \\
12.1 \\
12.5 \\
13.4 \\
14.7 \\
15.8\end{array}$ & 1 \\
\hline
\end{tabular}



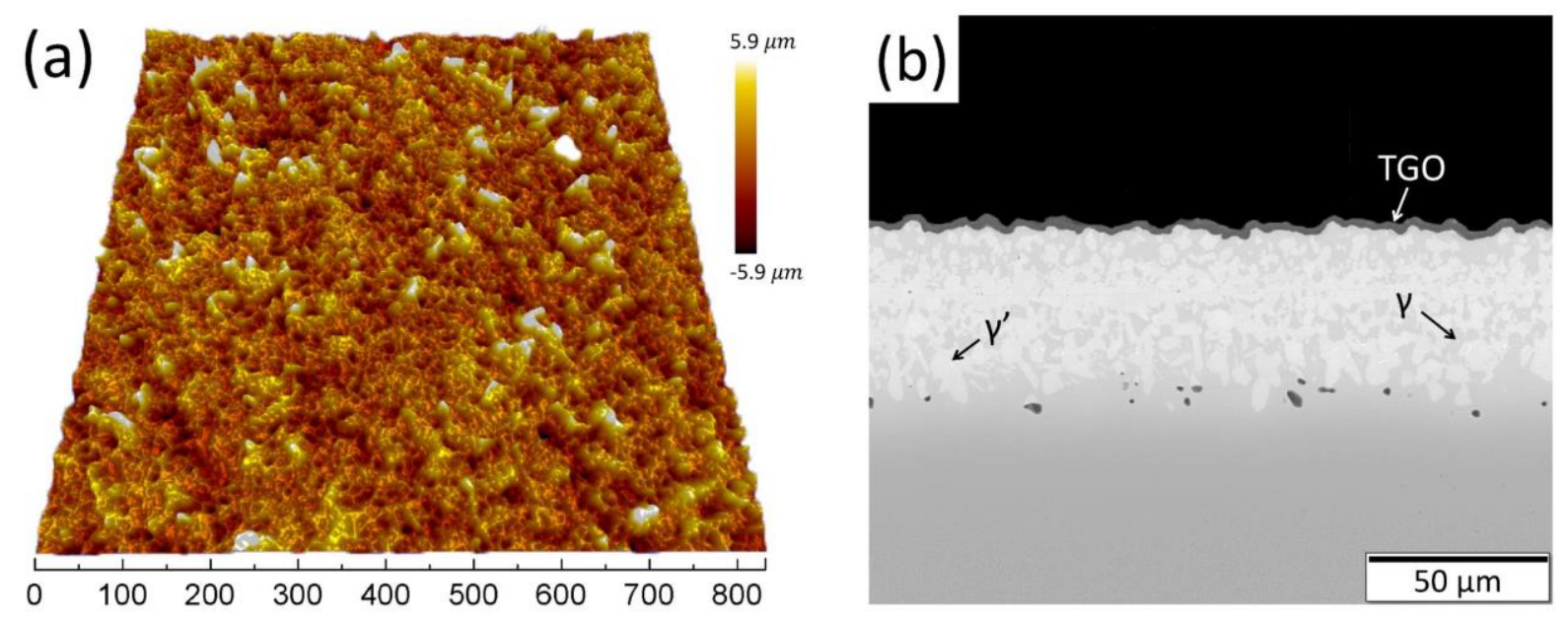

Fig. 1 

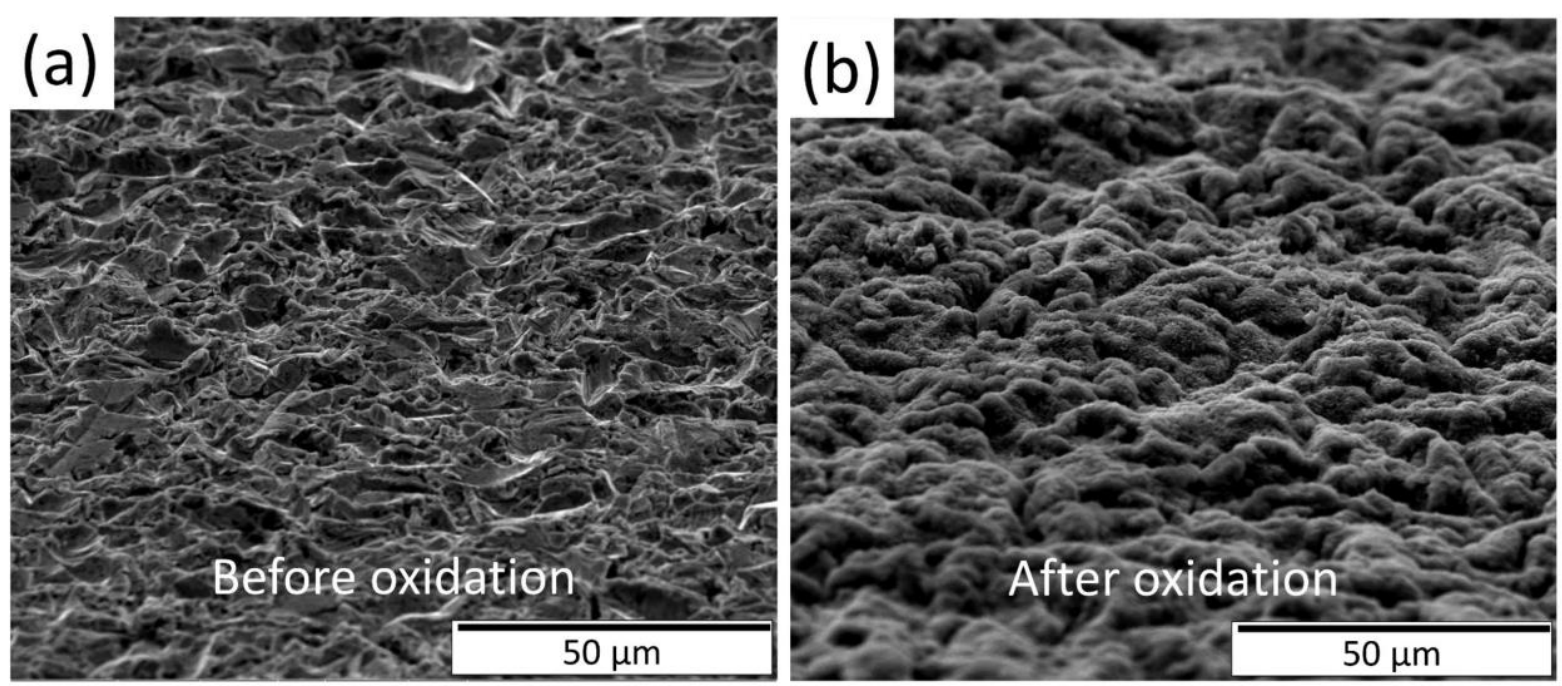

Fig. 2 
(a)

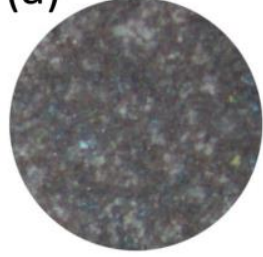

Omin (b)

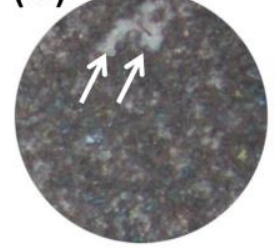

$30 \mathrm{~min}$ (c)

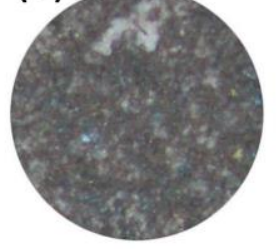

$50 \mathrm{~min}$ (d)

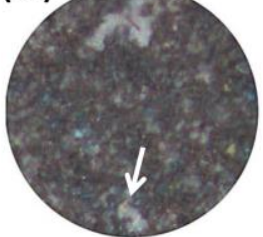

$2 \mathrm{~h}$ (e)

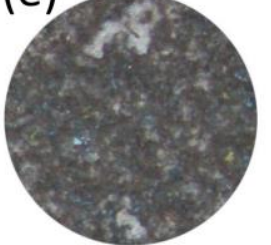

$24 \mathrm{~h}$

$$
200 \mu \mathrm{m}
$$

Fig. 3 


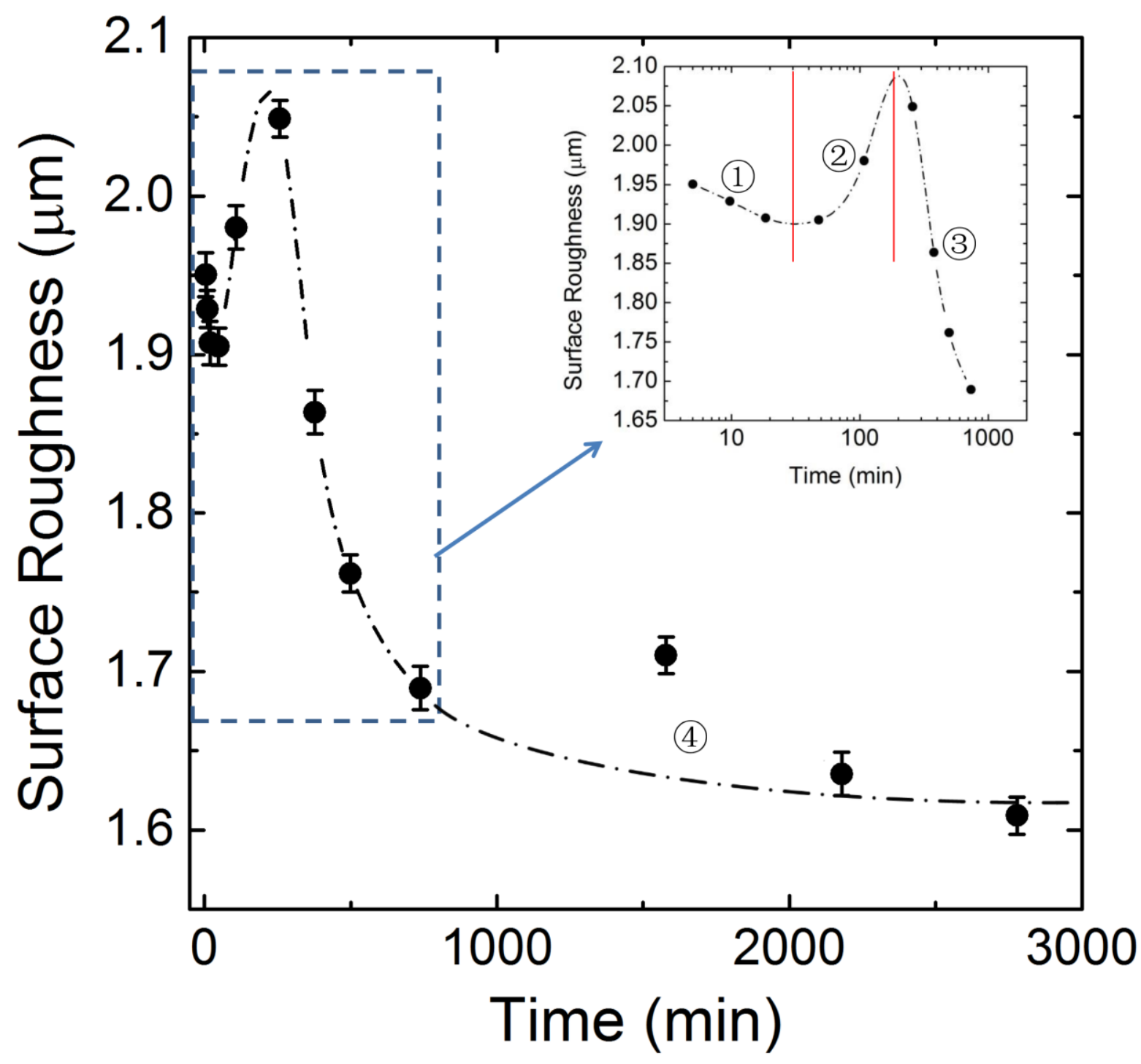

Fig. 4 


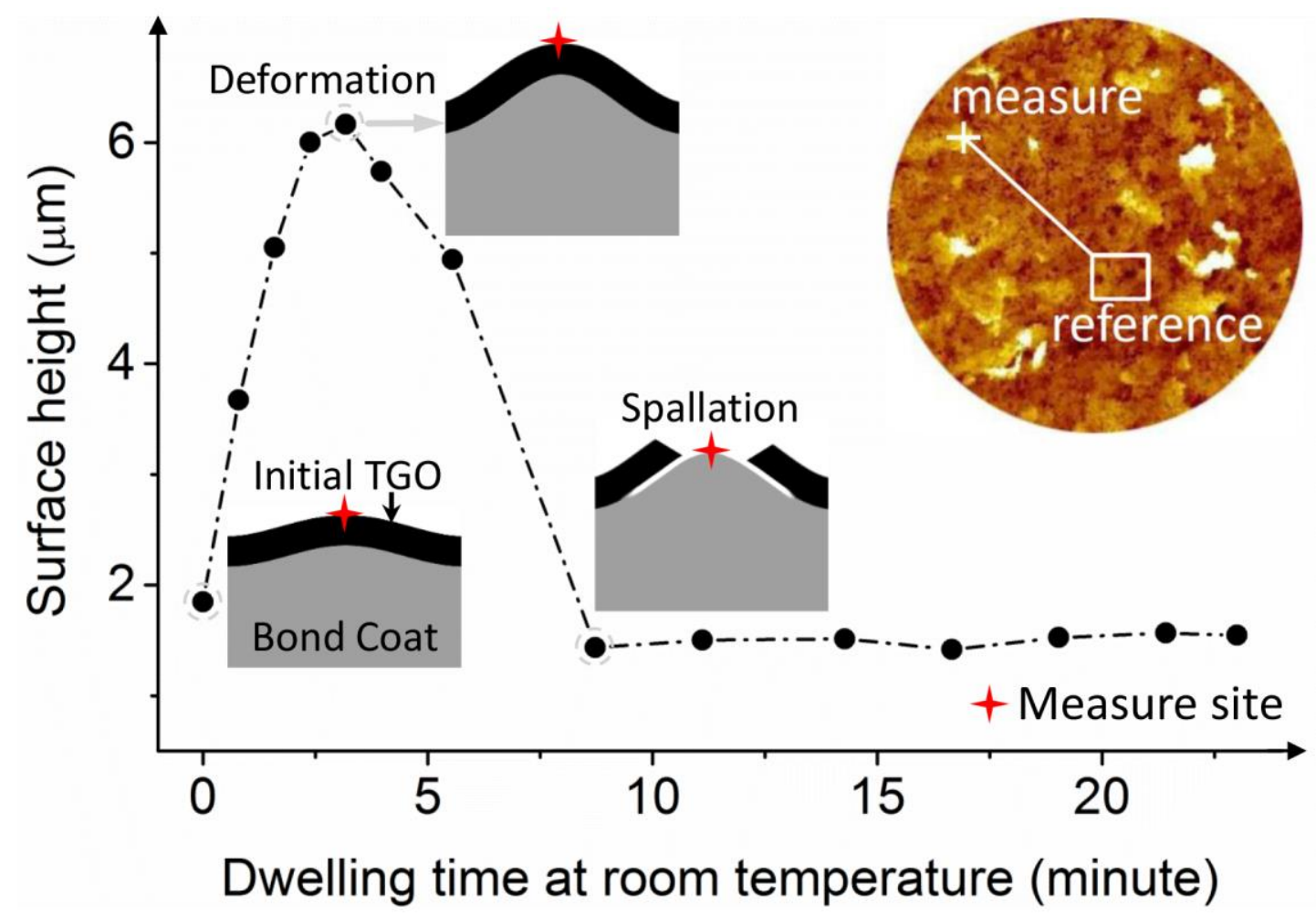

Fig. 5 
(a)
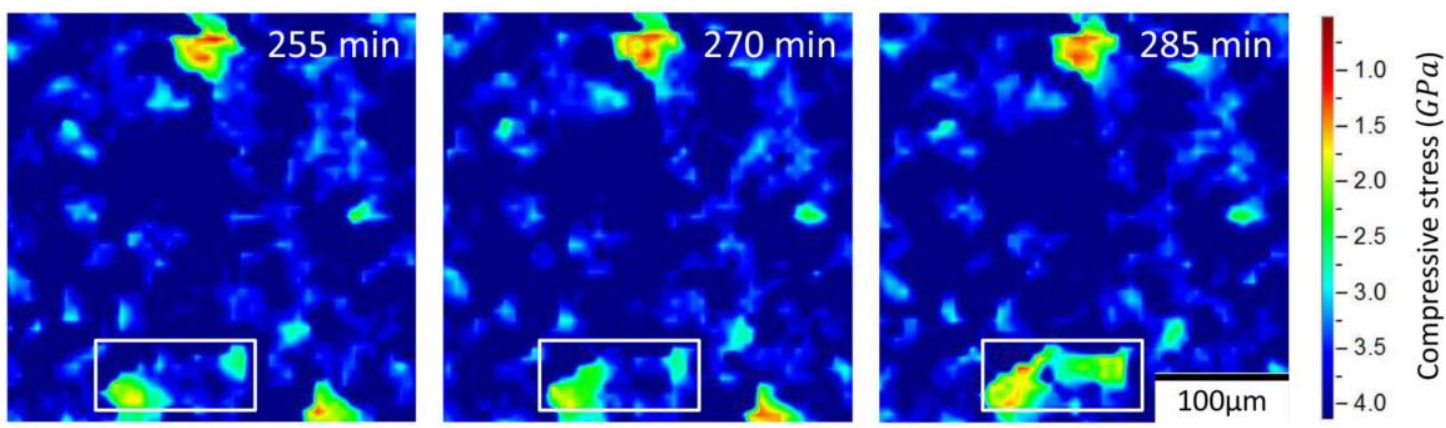

(b)

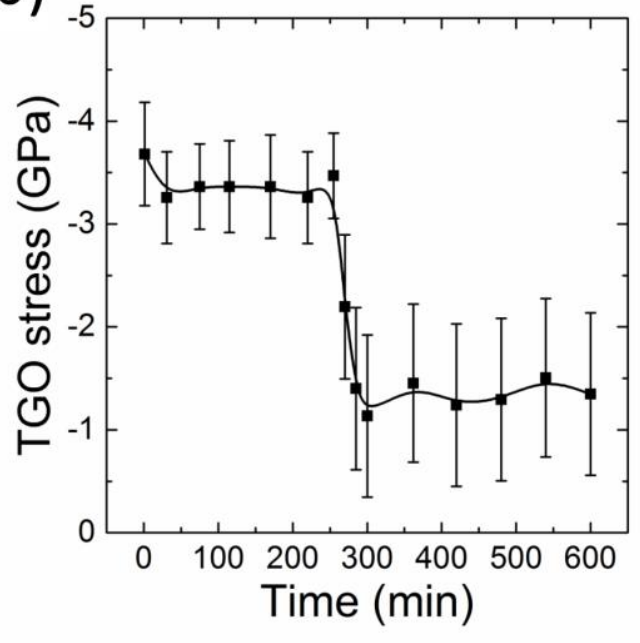

(c)

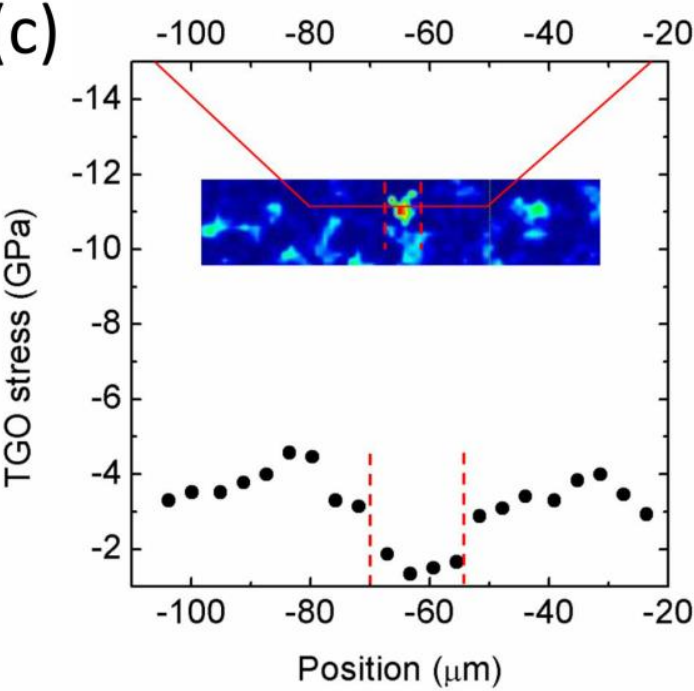

Fig. 6 


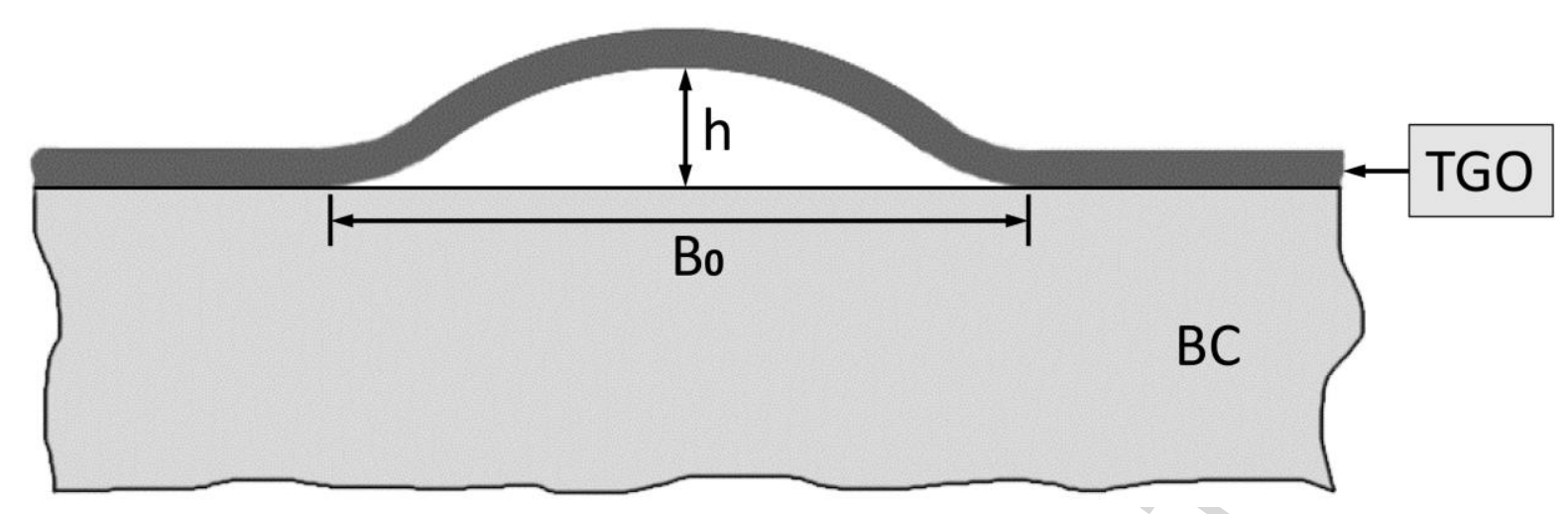

Fig. 7 
(a)

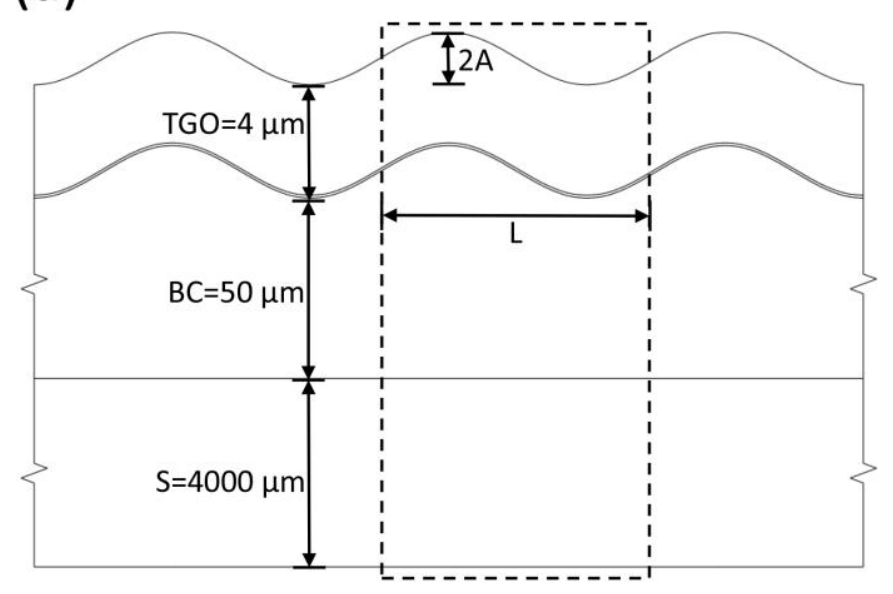

(b)

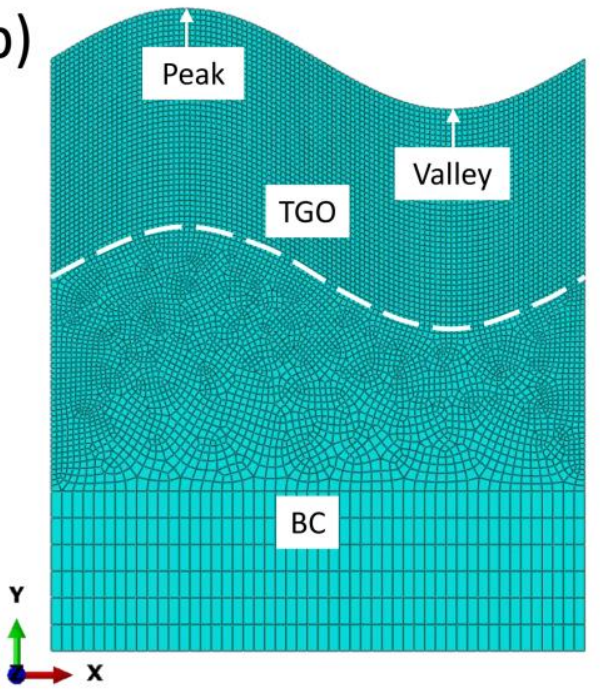

Fig. 8 


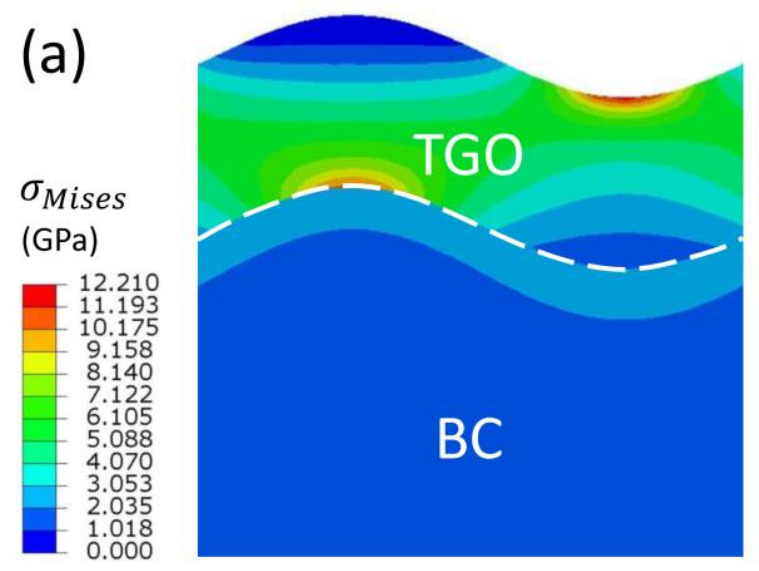

(b)

Fig. 9 
(a)

$\sigma_{\text {Mises }}$ (GPa)

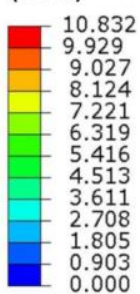

(c) $\sigma_{y}$
(GPa)

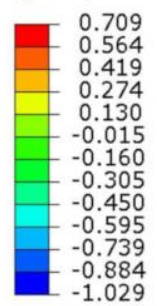

Fig. 10

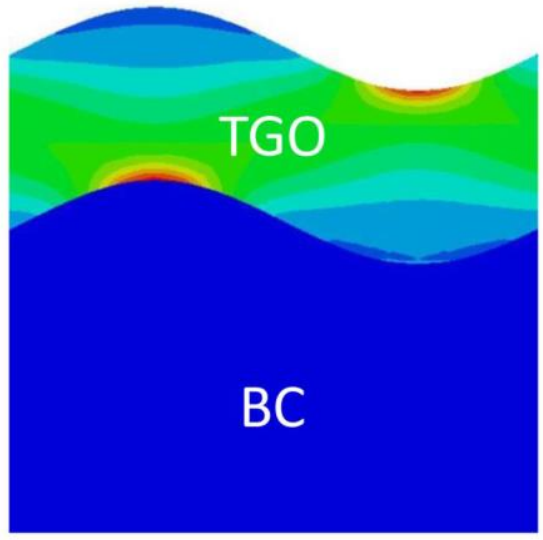

(b) $\sigma_{x}$ (GPa)

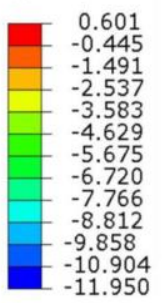

(d)
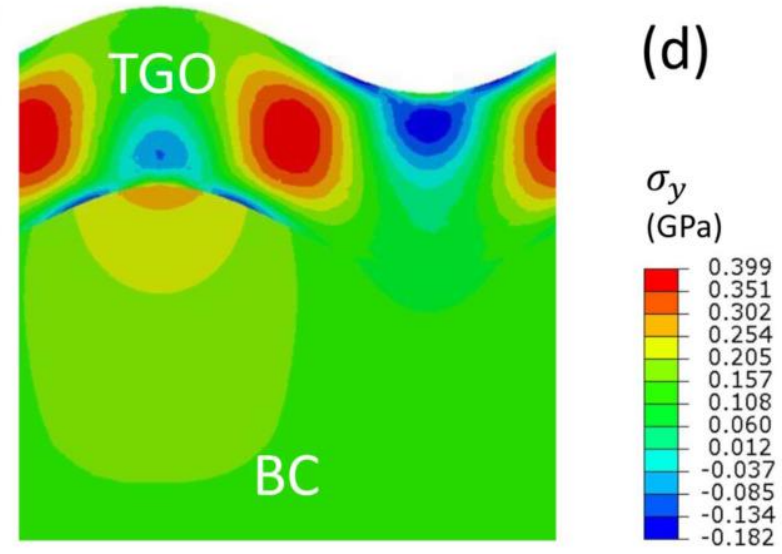
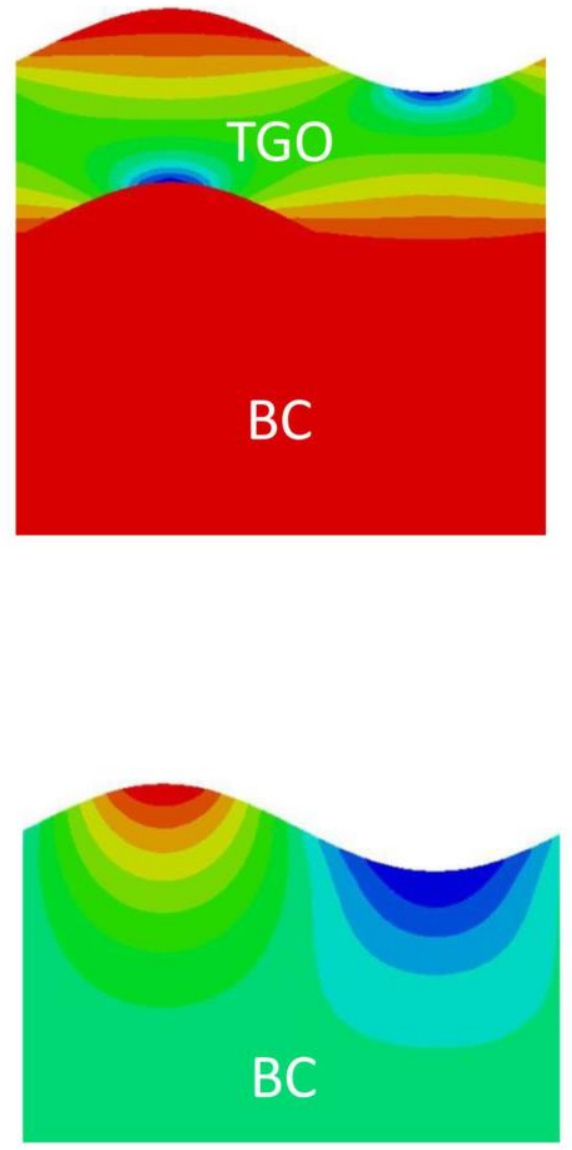


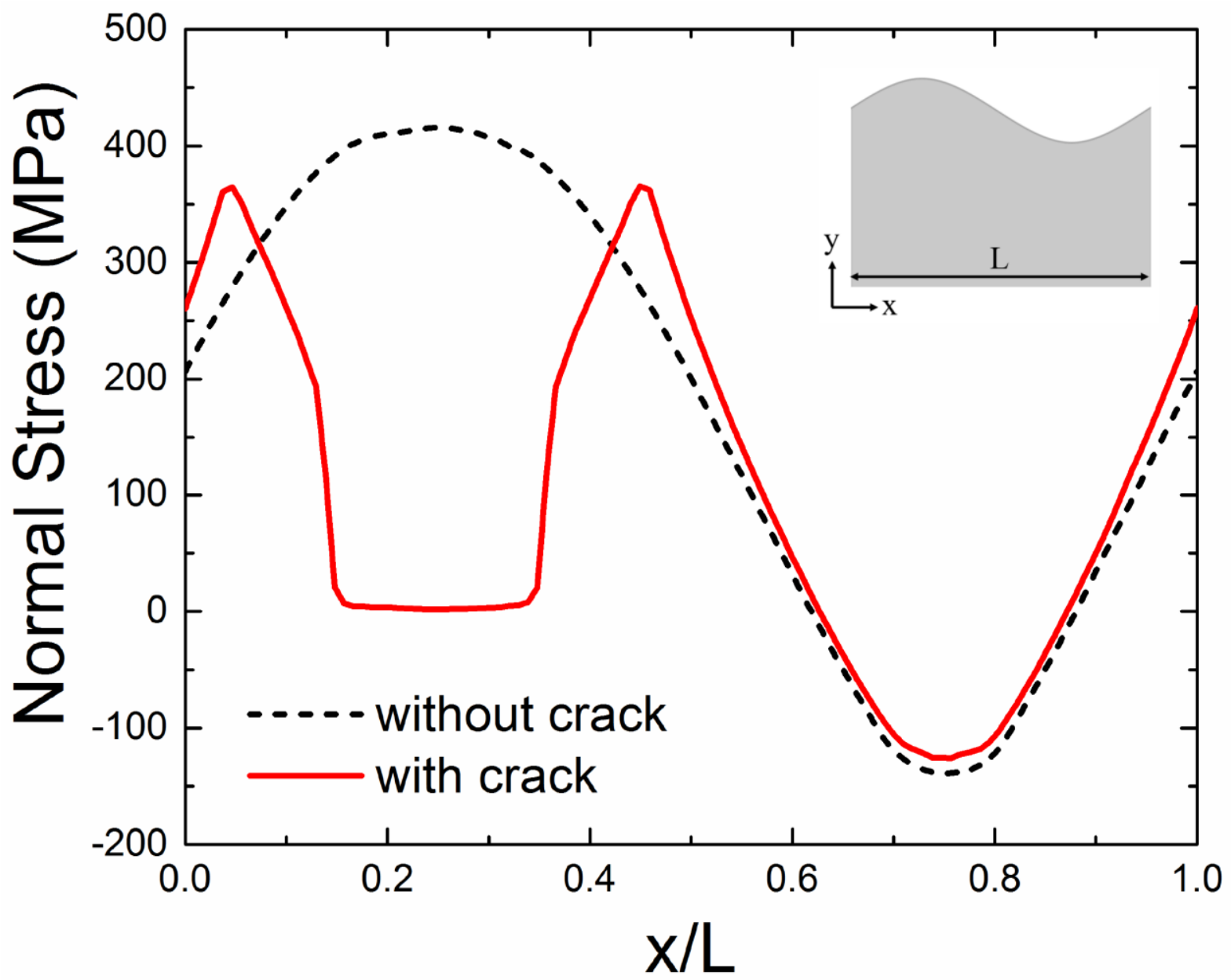

Fig. 11 


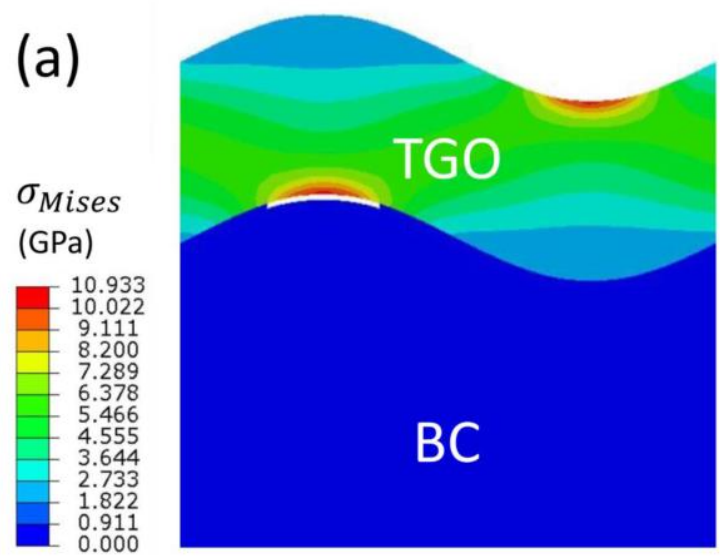

(b)

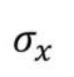

(GPa)

0.696
-0.363
-1.422
-2.481
-3.539
-4.598
-5.657
-6.716
-7.775
-8.834
-9.892
-10.951
-12.010

(c)

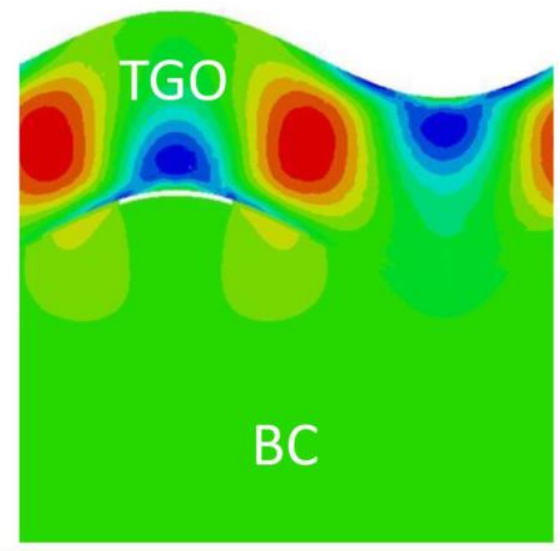

(d)

$\sigma_{y}$

(GPa)
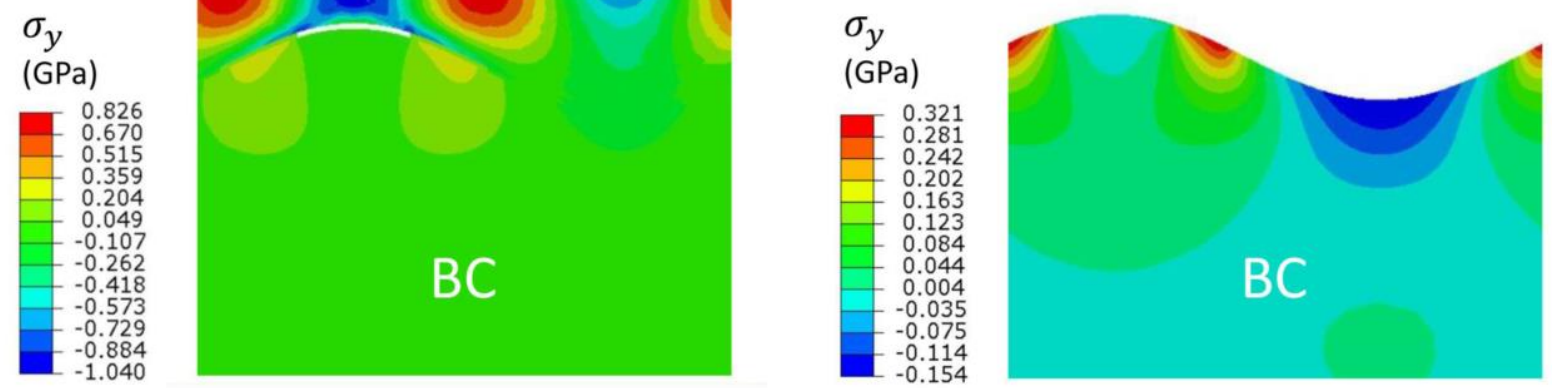

Fig. 12 


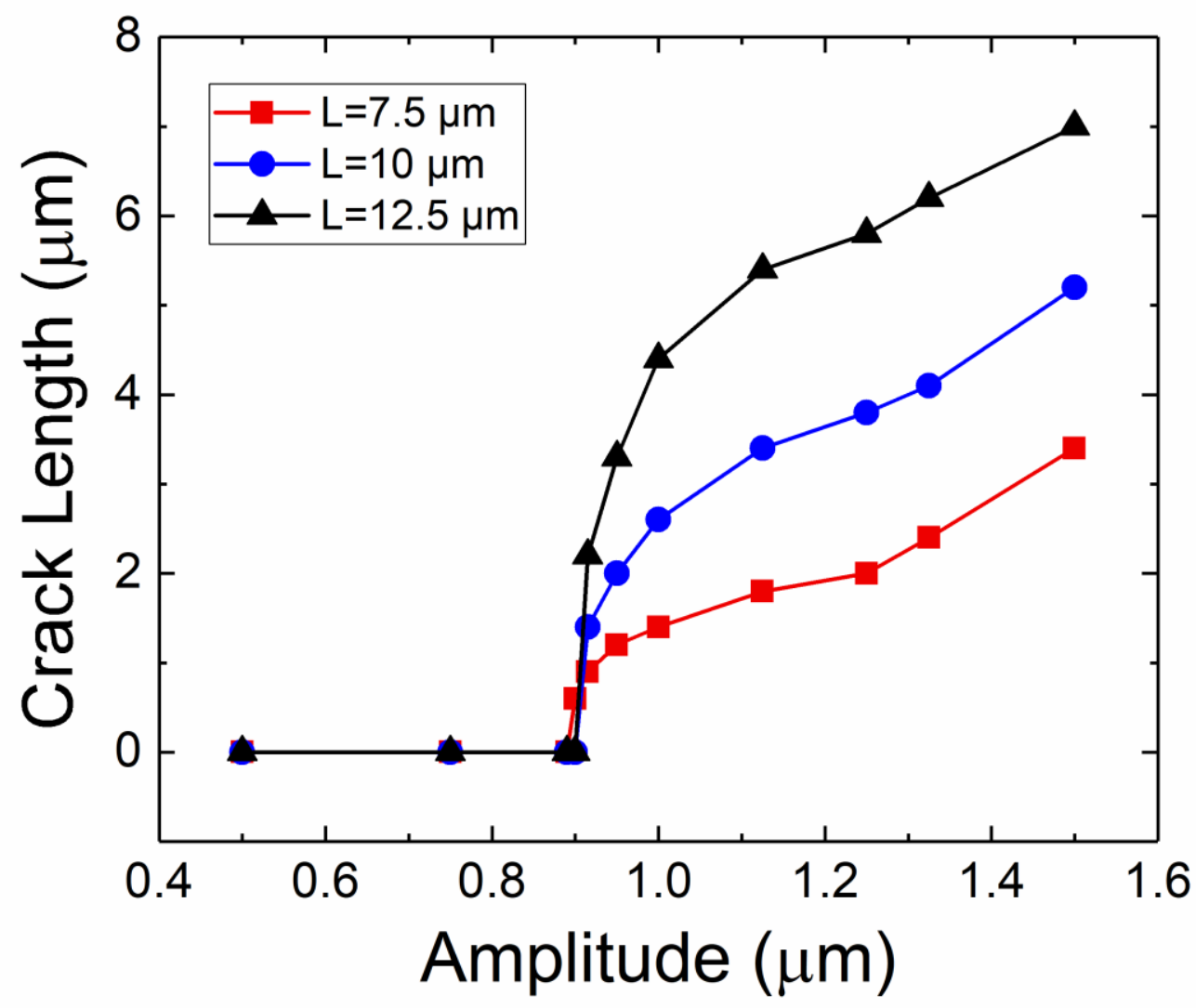

Fig. 13 


\section{Highlights}

-We found that the spalling of the TGO at room temperature exhibited a typical time-dependent behavior.

-The time-dependent spalling of the TGO might be associated with the local plastic deformation of the $\mathrm{TGO} /$ bond coat interface at the room temperature.

-The interfacial geometry was found to be a critical factor to affect the room temperature spalling of the TGO. 